\title{
Third Dimension Urgent Demand to Support Collaborative Learning in the Virtual Learning Environment VLE
}

\author{
Ahmed Dheyaa Basha ${ }^{1, *}$, Satar Habib Mnaathr ${ }^{2}$ \\ Center for Instructional Technology and Multimedia (CITM), Universiti Sains Malaysia, Penang, 11800 \\ *Corresponding Author: ahmed2009shh@yahoo.com
}

Copyright (C) 2013 Horizon Research Publishing All rights reserved.

\begin{abstract}
The main aim of supporting collaborative learning by multi devices such computer or Smartphone is to enable and induce students to work together. To confirm and verify their skills and knowledge by mutually interacting. And to foster their role in the social dimension. The virtual learning environment equipped with several features to support actual communication informally and to create communities. Many universities and organizations have been adopted to support distance learning. In this study we report on an experimental study that evaluated the importance of the value added by a second life platform grounded in meeting system to more collaborative learning activity, if compared to converging with the systems depended on synchronous text-based communication. The experiment outcomes explain that the adoption of a three dimension virtual learning environment does not upgrade the perceived level of repose with communication or introduce disorder during the activity, while the user perception of the majority of the features presented are positive.
\end{abstract}

Keywords DSCL, SL Platform, E- Conference, Support Collaborative VLE

\section{Introduction}

In the current time computer or mobile devices supported collaborative learning (DSCL) technologies more often based on electronic synchronous and asynchronous media. In this display of study, learning tests are focused on using artificial environments as well as it is suitable and very ease anticipate a prospective' future to increase adoption and new motivating settings for all distance learning and general of communications. Consequently the great mechanism effectiveness to collaborate in these domains is devices (computer or mobile) used to support collaborative learning (DSCL) as collaborative virtual environments (CVEs). These environments offered the high possibility to mimic the real world over create suitable ambiences for new imaginary worlds. Thus, continuation of interacting with these environments, users can actively experiment cases that are high benefits for comprehension concepts in addition to learning to achieve specific tasks. Moreover the metaphor of three dimensions for collaborative virtual environment meeting forums is used by several tools, such as [5][15][20]. All these tools represent a lot of collaborative by participants via avatars. While in [11] second life virtual environment the main control and setup of many collaborative learning activities has been suitably proposed. Number of researchers, such as [21,29][7], and a lot of organizations such as [3,11], emphasize that the three dimensions web virtual worlds may represent effectively a likely hypothesis on the perspective' future of the web applications and it can flexibly expect how contribute in evolution of web reconnaissance scenarios and describe the interaction metaphors will achieve more natural real world practices and explain much attitudes .according into many confirmations uninterrupted and high interest of academic filed and not just arbitrary interesting for the chances offered by virtual environments to collaboration,[23], report about the importance of using of second life (SL) for the yearly cycle of many program committee meetings such (IEEE Virtual Reality).these institutions concluded that (SL) is an applicable alternative to traditional education (face-to- face),it's possible to implement a meeting in SL and avert the spend time, efforts and money associated with face-to face. Virtual environments worlds such as Croquet [2], Active Worlds [18], Second life (SL) [13] and there, many suggest environments which are various, ranging from replicas of actual universities to other planets, or completely imaginary.

In this respect the interaction patterns suggested by virtual environments are perfectly of video game and web community, taken into account that future users in current time's digital natives', that is a help and leap in technological environments, such as online games and instant messages and applications of software used in learning and teaching in universities in the second life platform .Moreover it will be 
natural and interesting for them to apply virtual environment allows for collaborating.

The as a suitable paradigm for second life "world given depended on archipelago metaphor, where some of the islands are connected together across teleportation links, roads and bridges. Islands are populated by many users reincarnated avatars and gathering divers kinks of artifacts, ranging from big cities to small cars or fashion accessories [9, 13].usually the second life environment allows to build all three dimensional objects and equips as scripts with language LSL [11], LSL (Linden Scripting Language) is the scripting language that gives manner to Second Life primitives, objects, and avatars. This is a community effort to supply an accurate and open documentation resource on LSL for scenario of all skill levels, due to developing active behaviors. The three dimensions virtual environments are perfectly distinguished by three pertinent features: the user realization of the 3D space, the avatar can visually represent a participant and share to an interactive communication medium, bring more useful to support social connections $[1$, 31].

The virtual environments usually support strong communication based actions, learner textual or voice chats, and equipping several forms of content and easiest interaction. In this study our core research question is whether these features display an effective added suitable value to the collaborative learning activity in a second life environment as a virtual environment. Moreover many previous studies have been a lot of conducted for evaluating how contributing in rich interaction based on audio/ video technology or other traditional means different from based on interactive depended on single text-based channel. In spite of the passive premises of computer-mediated communication theories, the usefulness of text-based communication has been found also to acquisition on high advantage for remote group collaboration, as in the situation of extracting and negotiating different software requirements $[12,27]$,[].for instance, text- based collaboration has been found to enhancing and improve specific communication many aspects, like the comfort with a lot of communication absorbed by stakeholders ( e.g., lower peer-pressure)[5,17].Meanwhile and in [2] gave evidence that specific collaborative settings truly exist, distinguished by minimized information loads, once synchronous, text-based communication was sufficient to attain a public ground among conversational learners unknown to each other.

In this study we evaluated the added value equipped with second life based (DSCL) system, during a lot of collaborative learning activity as compared to a meeting system which depended on synchronous text- based communication. Especially some attention grounded on devoting to verify that contribute in richer environment and avoid other factors could affect the learning.

\section{Technological Glances}

To assess the effectiveness of a virtual environment in supporting collaborative learning taken into account a pure textual point of view, we chose the two importance systems in short described in the following:

\subsection{Effectiveness Second Life to Create Meeting}

Of late the many departments in different universities for several programs such Mathematics and Informatics engaged a lot of instructional experiments adopting second life to create and establish the distance learning activities such USM . Meanwhile and in [10] we highlight on a virtual campus, called DMI [24], established by using the second life platform. We assessed the perceived sociality of the suggested environment and outcomes proposed that it contribute in flexibly the comprehension of social spaces with many attributes as a confidence and pertinence. In addition into a deep sense of community is also perceived, in overall Second Life DMI has also been provided with a suitable collaborative learning environment, explained in $[14,16]$, called second life meeting, to improve and support SL with meeting ground control and high management features.

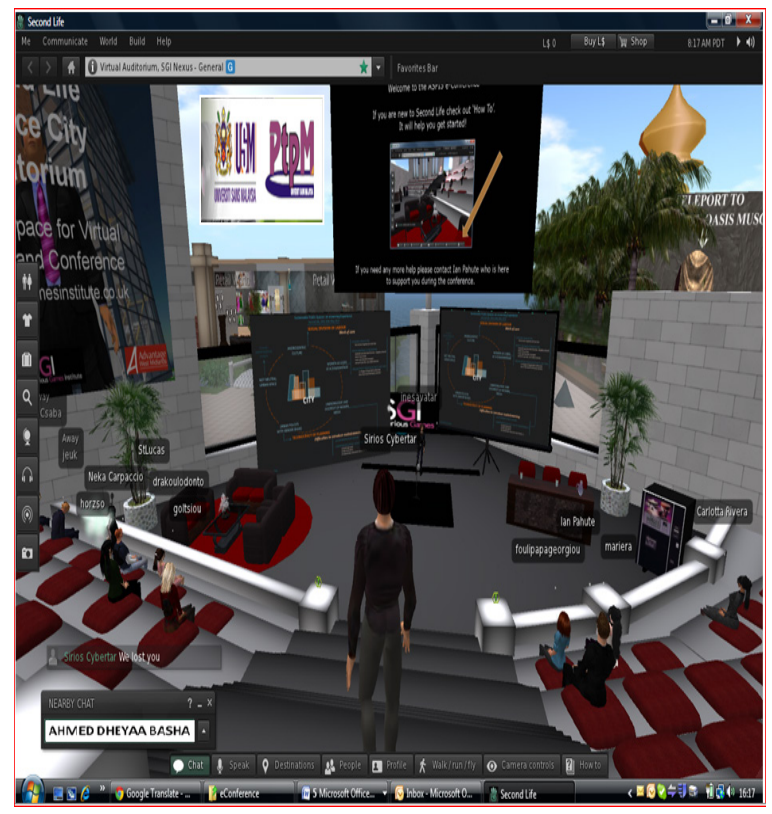

Figure 1. Display Effectiveness Second Life to create Meeting

In this respect and in specially, a collaborative learning activity entails several introductory phases such as the delivery of the material to the learners, tracking the role assignment, the communication of the activity start time , place and date .In addition to the special session closure has to be supported. This new environment will help to enable to control the meeting over interactive and ad-hoc which contributed in developed SL objects. Each learner can use this space to synchronously work with each other as a team. An example of effective collaborative setting is displayed in Figure 1. A learner is chosen as leader of some of the group: their seats in the center of the table at the leader control bar, 
and their avatar wears the leader characterized shirt. Meanwhile the nod bars, as displays in Figure 1, and facilitates non- verbal communication and contributes to minimize distraction. As a suitable example, the hand - raise button helps and enable learners to book their interferences, which eventually are scheduled and showed on a booking list blackboard. The final aim is to build the actual needed knowledge to enable each learner to report on material or topic determined by their instructor.

\subsection{E- Conference via Second Life Platform}

In this system the text- based conferencing tool that has been enhanced and developed at the university science Malaysia USM as part of a broader research effort with the goal to support the collaboration and interaction of ad- hoc, aim - oriented work group, which require low-cost management infrastructure only to integrate the task at hand $[22,28]$. It enables the meeting leaders to explain the roles of the users and equips each role with the convenient view. It also presents a closed group chat together with the agenda. While white boarding, meeting minutes editing and typing much awareness capabilities and helps regulators to set up a meeting and to high control and effective discussions. Meanwhile the tools windows are organized in six major areas and options: the agenda, the message board, the input panel, the hand raising panel, the edit panel, and the presence panel (display in Figure 2), while (Figure 3) explain the role of collaborative learning via e- conference and how the participant has been invited. The agenda or schedule point to the case of the meeting, in additional the current items under discussion. The input panel will enable all participants to add and send many statements during the multi discussion. In this respect the message board considers the space where the meeting discussion takes place. While the hand raising panel as another feature is used to enable turn-based discussions among participants. The edit panel showed a summary of the discussion.

The presence panel displays which users are currently logged in and their role in these discussions. Eventually, the hand raise panel simulates the hand raises social protocol that people use over actual meetings to coordinate discussion and finally turn taking. Meanwhile the hand raises feature of e -Conference also will contribute in giving to the tester the ability to preview a series of questions. e-conference has been used in the USM form to sharing with other universities under special circumstances to conduct the meeting, presentation and e-Conference, to run a controlled experiment on the comparison between co-located and synchronous text based interaction, on the menu of distributed requirements in different filed $[17,6]$. In this study we would remind that in second life it is not possible to save or replay the conversations, as a result, workspace awareness. This feature has been completed in the second life meeting platform by an ad-hoc Moodle plug-in useful to record the knowledge created by the learners using connectivity over chat, to equip all the informative information regarding the event and to enable the instructor to set up the collaborative session. The outcome of the combination between second life and the Moodle plug-in is a system that reliably enriches all Second life environments with LMS services and synchronizations over collaborative learning. In the end up, it is very important to refer that the system, even if in a three dimension environment, equips students with whole information related by textual boards to be shown.

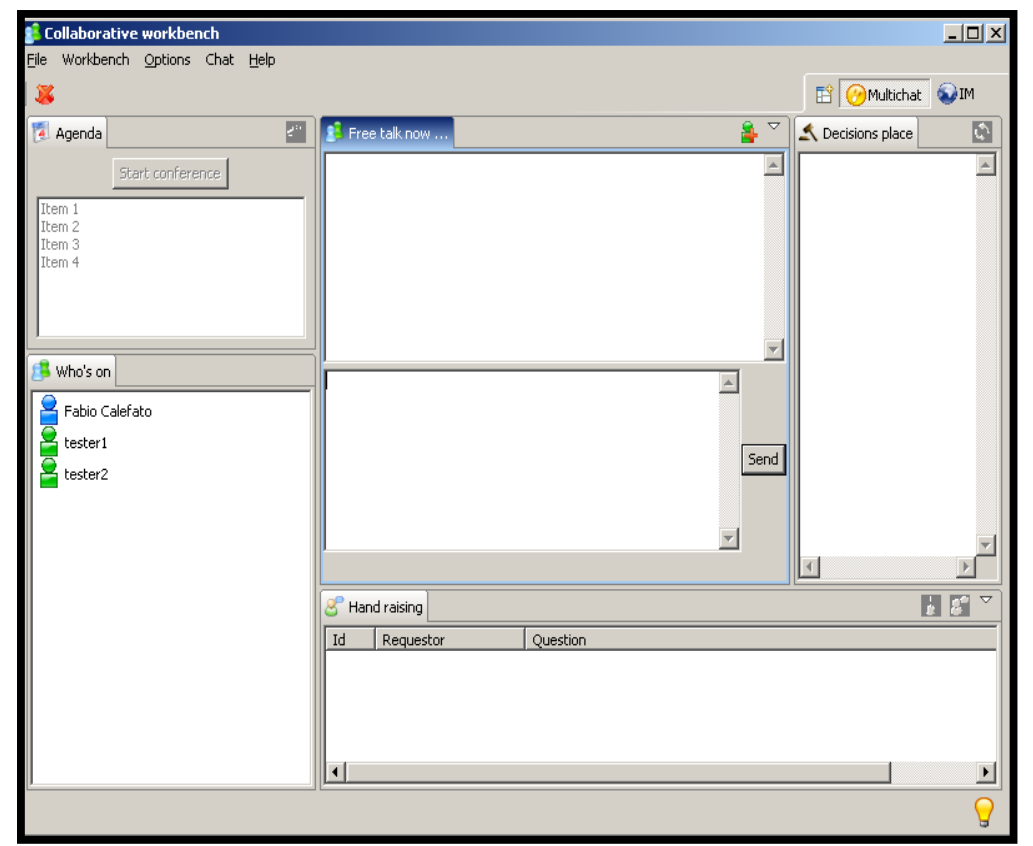

Figure 2. Show the e-Conference tool 


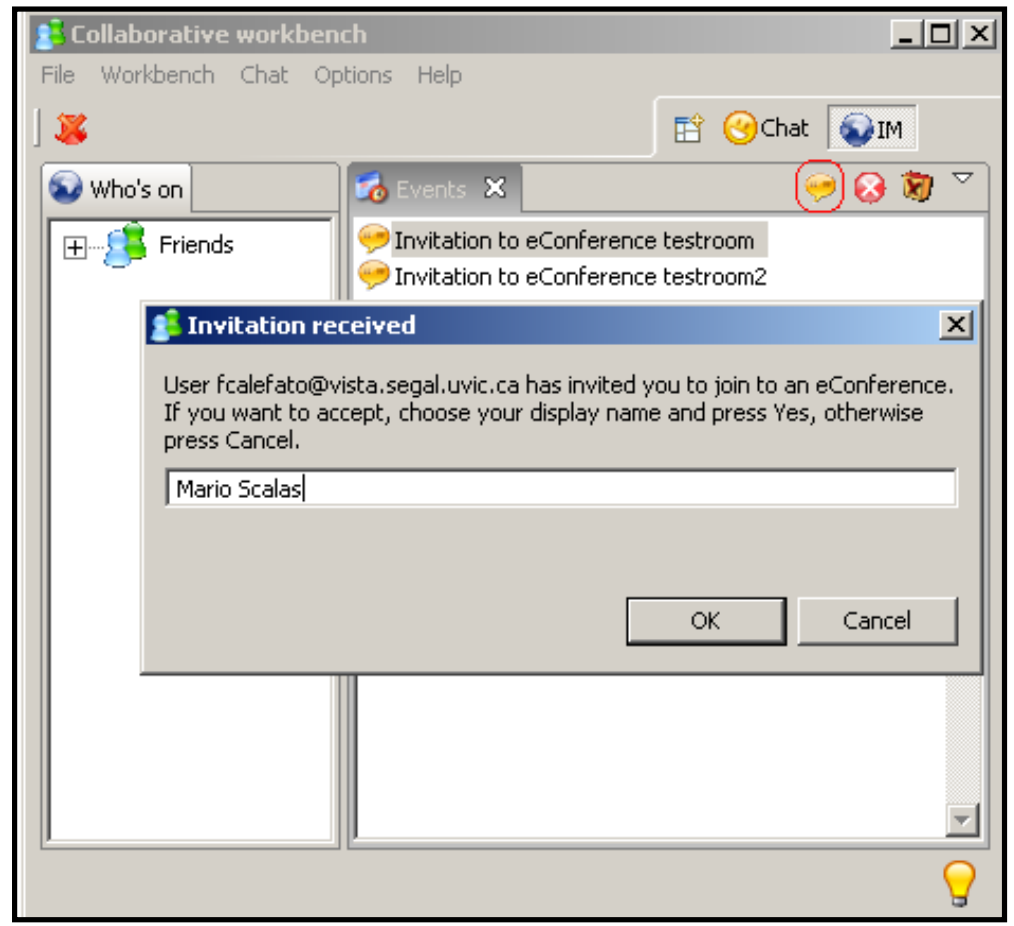

Figure 3. Display how the participant has been invited

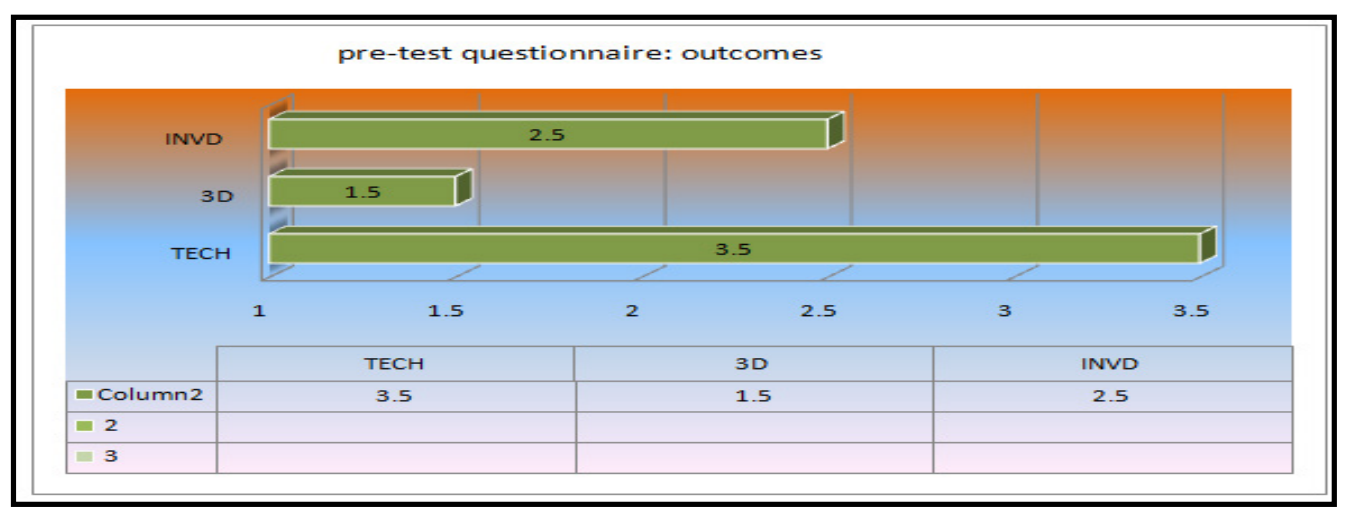

Figure 4. The pre-test questionnaire: outcomes

\section{The Experimental Test}

All a collaborative sessions have been regulated as a controlled test aiming at evaluating the use of the suggested second life collaborative learning point of view as compared to a meeting caught over a text-based conferencing system. In this test the participants were students of the computer sciences and instructional technology and multimedia at the USM to conduct the test. The controlled test has been performed by template proposed by some other researcher to previous study such $[20,8,25]$.

\subsection{Definition of Experience and Context}

A collaborative learning activity performed by small teams has experimented with using the tools identified in the number of students (26 students) from USM, who volunteered to participate in the Experimentation. It was a pre-trial questionnaire Suggested to them to assess their background in the using of Computer to connect to (TECH), and Video Games 3D applications (3D) and the level of their attitude of their participation (Investment). Data collected during the experiment, before the main background questionnaire In Figure 4. Answers to the survey questionnaire have been assessed on a Likert scale of five points, anchored with Values $1=$ very low, $5=$ very high [20, 3, 19]. (Figure 4) describes the Background skill of the learner, in terms of technology (both PC or Mobile and 3D) capabilities and the level of attitude to be involved.

To achieve Harmonization 3D experience among the participants, players received SL novice to fast before the start of training evaluation. In addition to that provided all of the systems on the threads. After the end of the test course students were grouped randomly into four teams, which are composed of seven articles, and some of the other six.

The experiment was conducted on the Internet in 
University of USM in computer science and center of instructional technology and multimedia. In the sense of "presence" and "awareness" is nature is seen as much stronger in a $3 \mathrm{D}$ environment than in a two-dimensional conversation. Thus, we I decided to investigate the difference between TXT and SL Cooperative learning to check whether there is the presence of some advantages in the use of $3 \mathrm{D}$ environments relation chats $2 \mathrm{D}$ in the case of cooperative activity on the basis of negotiation. The specific tasks in which subjects had to perform required inferring from the property set of rules. The solution was to be the product of collective Debate because each group was to provide a unique product. It was expected to be completed within each task one hour. In particular, E1 is a puzzle task proposed Einstein, who said that $98 \%$ of people in the world cannot be solved it $[13,15,9]$. And E2 is a puzzle task is similar in terms of the of difficulty. The common feature of the selected tasks is that there is a need for cooperation and discussion to reach a solution. Two different teaching methods, a TXT (In collaboration with e-Conference) and SL (cooperation Using SL Meeting), and used for the Group's performance Collaborative sessions. Both methods have been applied to each of the tasks.

\subsection{Design Method}

In order to compare SL and TXT educational properly methods and outcomes analysis, we considered only two Independent variables, a method (SL and levels of (TXT) and mission (levels of tasks E1 and E2).

To compare the specific technologies, we considered the dependent variable result that was obtained through questionnaires served after each of the SL and TXT lab sessions and after the whole experience. All sets of factors, the method (SL and TXT) and tasks (E1 and E2), have been taken into account when the design of the experiment. To avoid the results to be biased by the difficulty of the task, and the ability and the impact of group learning, all Possible replacements TXT or SL treatment, and the task ordering and tried by a single group. Table 1 summarizes the experimental design, where Ti_Mi refers to a set of tasks and method of implementation by teams in test cycles. In addition we randomly assign some of members to groups A, B, C, and D.

Table 1. The Design Method

\begin{tabular}{|c|c|c|c|}
\hline \multicolumn{4}{|c}{ Groups } \\
\hline A & B & C & D \\
\hline Task E1_SL & Task E1_TXT & TaskE2_SL & Task E2_TXT \\
\hline E2_TXT & E2_SL & EI_TXT & E1__L \\
\hline
\end{tabular}

\subsection{Planning Attended an Introductory Lesson Topics Provide and SL Meeting and Systems E-Conference. This Training Session Aims to Provide All The Material with Sufficient Prior Knowledge on the Use of Two Cooperative Tools}

Provide training courses conclude detailed instructions about the tasks to be performed. At the end of each session, the same survey lab questionnaire, as shown in Table 2, has been proposed for the subjects. To summarize the impact of communications Cooperative learning methods on the road to subjects' Visualization, we visualize three structures [3, 11, 13] It is namely involvement INVO, comfort with communication.COMM put communication, material and the environment organization ORGA, the communication category has classified to be considered as a control factor because these questions have been added to easily check whether the error of the experiment conducted, and then annul the outcomes. The last three questions of the questionnaire tasks post have been developed to evaluate and have interfaced a quick resumption impression on each system. At the end of each task, each subject has to fill the questionnaire reported in Table 3, contain some additional assessments that directly contribute to the assessment of comparison between the two approaches answers to the survey questions two based on questionnaires again on the same five-point Likert scale.

Table 2. Show post -task questionnaires

\begin{tabular}{|c|c|c|}
\hline $\begin{array}{l}\mathrm{N} \\
\mathrm{O}\end{array}$ & QUESTIONS & $\begin{array}{l}\text { Constru } \\
\text { cts }\end{array}$ \\
\hline Q1 & $\begin{array}{l}\text { I had enough time to perform the required activity in } \\
\text { SL platform }\end{array}$ & ORGA \\
\hline Q2 & $\begin{array}{l}\text { The activity objectives were very clear to me and to } \\
\text { collaborate with my colleagues. }\end{array}$ & ORGA \\
\hline Q3 & $\begin{array}{l}\text { The activity to perform was very clear to me and to } \\
\text { collaborate with my colleagues. }\end{array}$ & ORGA \\
\hline Q4 & $\begin{array}{l}\text { The materials I received was enough to perform the } \\
\text { activity and collaboration }\end{array}$ & ORGA \\
\hline Q5 & The task to perform my duty was very easy and clear. & ORGA \\
\hline Q6 & Communicate with my colleagues was easy. & COMM \\
\hline Q7 & $\begin{array}{l}\text { The opportunity to share in the discussion was } \\
\text { suitable. }\end{array}$ & INVO \\
\hline Q8 & $\begin{array}{l}\text { I actively participate for the experience in the SL } \\
\text { platform. }\end{array}$ & INVO \\
\hline Q9 & $\begin{array}{l}\text { I have been encouraged to discussion contrasting } \\
\text { solutions to my colleagues. }\end{array}$ & COMM \\
\hline $\begin{array}{c}\text { Q1 } \\
0\end{array}$ & $\begin{array}{l}\text { The other students adequately answered to my } \\
\text { communications neatly. }\end{array}$ & COMM \\
\hline $\begin{array}{l}\text { Q1 } \\
1\end{array}$ & $\begin{array}{l}\text { I felt myself improve during the test in the SL } \\
\text { platform. }\end{array}$ & INVO \\
\hline $\begin{array}{l}\text { Q1 } \\
2\end{array}$ & $\begin{array}{l}\text { While I conducted the activity I had the sensation to } \\
\text { lose time and efforts. }\end{array}$ & INVO \\
\hline $\begin{array}{l}\text { Q1 } \\
3\end{array}$ & $\begin{array}{l}\text { It has been flexible to reach a common decision } \\
\text { inside my group to collaborate. }\end{array}$ & COMM \\
\hline $\begin{array}{l}\text { Q1 } \\
4\end{array}$ & $\begin{array}{l}\text { The information available on the screen were } \\
\text { disposed in a logical way and smooth. }\end{array}$ & \\
\hline $\begin{array}{l}\text { Q1 } \\
5\end{array}$ & $\begin{array}{l}\text { If I can, I will systematically use this instructional } \\
\text { approach in the future. }\end{array}$ & \\
\hline $\begin{array}{l}\text { Q1 } \\
6\end{array}$ & My general impression is positive. & \\
\hline
\end{tabular}


Table 3. The Post-Test Questionnaire Appendix

\begin{tabular}{|c|c|c|}
\hline $\mathrm{NO}$ & Questions & Construct \\
\hline Q17 & $\begin{array}{l}\text { Students' avatars were an adequate representation } \\
\text { of the human entity. }\end{array}$ & AVA \\
\hline Q18 & $\begin{array}{l}\text { The virtual environment design was suitable to } \\
\text { motivation. }\end{array}$ & CVE \\
\hline Q19 & It was flexible to distinguish the student' avatars. & AVA \\
\hline Q20 & I was realized of the existence of my avatar. & AWN \\
\hline Q21 & It was flexible to control my avatar. & $\mathrm{DF}$ \\
\hline Q22 & $\begin{array}{l}\text { I had less distraction using SL Meeting in my } \\
\text { experience. }\end{array}$ & $\mathrm{DF}$ \\
\hline Q23 & $\begin{array}{l}\text { I had less distraction using e-Conference in my } \\
\text { experience. }\end{array}$ & $\mathrm{DF}$ \\
\hline Q24 & $\begin{array}{l}\text { Non verbal communication (nod) facilitated my } \\
\text { collaboration with the others. }\end{array}$ & COMM \\
\hline Q25 & $\begin{array}{l}\text { Non verbal communication has constructed } \\
\text { distraction. }\end{array}$ & $\mathrm{DF}$ \\
\hline Q26 & $\begin{array}{l}\text { Working as a group activity has had the } \\
\text { advantages of the virtual environment. }\end{array}$ & COMM \\
\hline Q27 & $\begin{array}{l}\text { Working as a group activity has had the } \\
\text { advantages of the textual environment. }\end{array}$ & COMM \\
\hline Q28 & $\begin{array}{l}\text { I think that the inserted value of the virtual } \\
\text { environment is useful. }\end{array}$ & CVE \\
\hline Q29 & $\begin{array}{l}\text { If I should select a meeting environment I will } \\
\text { prefer SL Meeting to connect and collaborate. }\end{array}$ & \\
\hline Q30 & $\begin{array}{l}\text { If I should select a meeting environment I will } \\
\text { prefer e-Conference for my actions. }\end{array}$ & \\
\hline
\end{tabular}

\subsection{Materials and Implementation}

Teams completed each session of the laboratory experience in one hour. For all testing the subject with the following materials required:

1) Introductory lecture slides presented in the paper

format (TXT) or pre-imposed by the provider of the slides (SL);

2) Guidelines for the implementation of the tasks assigned;

3) Problems to be solved collaboratively in two tasks, in the form of paper (TXT) or previously charged to the slide provider (SL);

4) The report is adopted for reporting results;

5) The survey questionnaires to be filled in at the end of each laboratory session.

6) Recent experience questionnaire in addition to be prior to the close of the experiment.

\section{Assessment}

To let the post two tasks the results of the questionnaire's compare SL and e- Conference environments from the user through the evolution of perceptions that have been collected during the experiment. Figure 5(a,b) explained the aggregate in three constructs the answers user related in SL meeting and e-conference consecutively : their sense of Involvement (INVO) in the experience of (investment), and the quality of and support submitted to the communications (COMM) and the organization of the experiment (ORGN).

On the face of the particular, the upper part of the image describes the outcomes SL Meeting in the while that less and one resumes e-Conference performance. In the context of the communications is based on two texts, on the alike seems to technologies to be seen the same way. And we are referring to disperse the difference in the category of COMM which reveals the views of the user about communication support. Of SL Meeting to be a little more of the various views on the environment e-Conference.

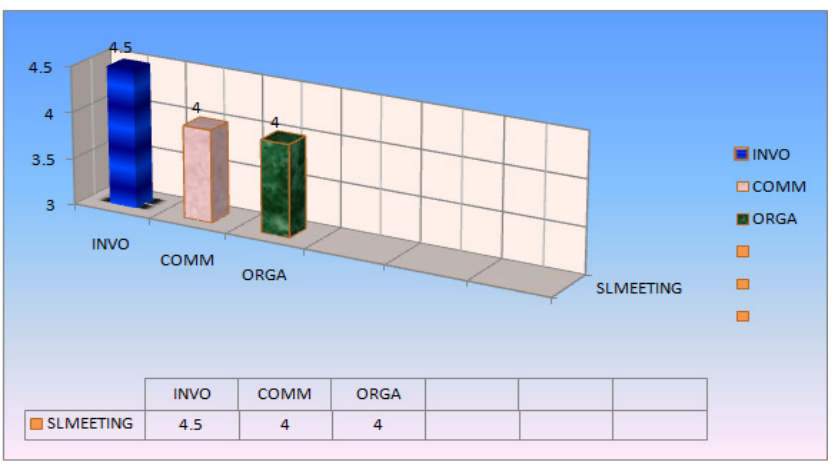

Figure 5(a). The post-test questionnaire (SL Meeting): outcomes

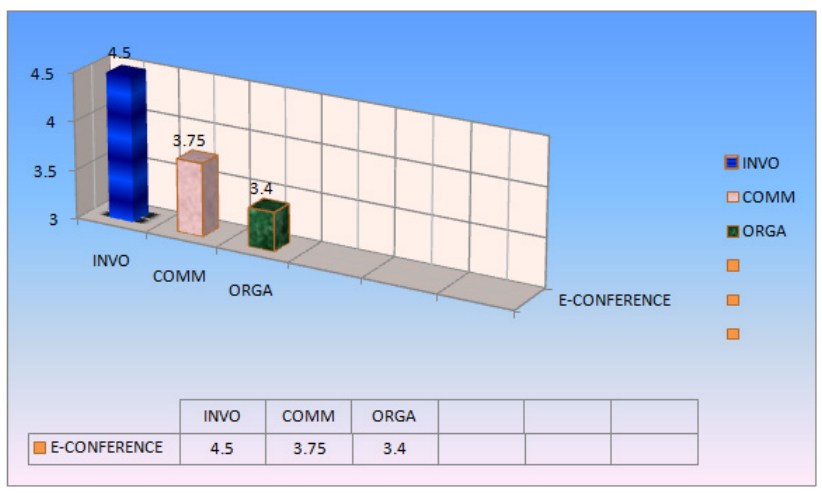

Figure 5(b). The post-test questionnaire (E-Conference): outcomes

In addition a questionnaire after we experience put three main pairs of questions designed to direct evaluation of interventions could be 3D environment may insert to the usual channels of communication such as text chats. Indeed, the environment e-Conference willingness to focus on the students' actions and the flow of the meeting, while SL Meeting of leaving learners free to choose their own perspective on the work. The proposed experiment aims to verify that this flexibility and freedom, especially with the novices, and when they are inglorious in a richer environment than is strictly required, may disrupt their attention eventually. The first pair of questions is Q22, Q23 and that gave us the data to evaluate whether SL Meeting, in environment general SL, and the introduction of elements selected of disturbance in an environment which needs only 
the textual information. The questions focused on a distraction, and may be connected with test the hypothesis succession:

H0: Does not add elements meeting disruption the e-conference.

H1: SL Meeting adds elements of the disabled e-Conference the result has been obtained from the pairing Turn t-test $(\mathrm{p}$-value $=0955)$ does not allow us to reject H0.Questions Q26 and Q27 the aims to directly compare Communications support provided by two Environments. Also in this case we can formulate two assumptions:

H0: SL Meeting not collective lack of communication support compared with e-Conference Lacks SL Meeting in Communications Support.

Lacks SL Meeting in Communications Support Group: Compared with e-Conference.

H1: the SL Meeting lacks in group communication support if compared to e Conference. In addition, also in this situation, the $\mathrm{t}$ test $(\mathrm{P}$-value $=0.900)$ equips evidence to abandon the null hypothesis H0. Figure 6 resumes individual differences among Dozens SL Meeting and e- Conference provides

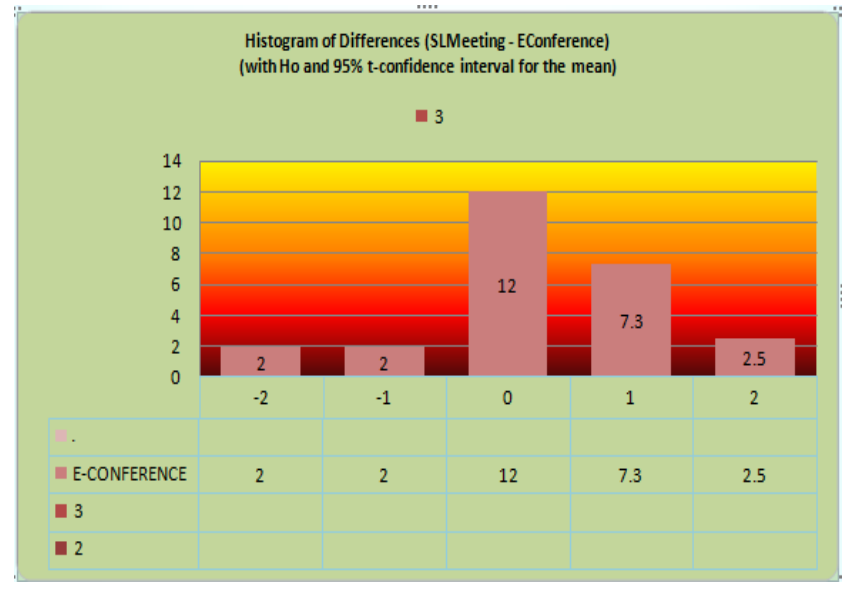

Figure 6. The Histogram of the differences perceived by users from students and assessment by questions Q26 and Q27

An estimate the average interval. Chart describes detects a little bit better perceptions reached SL Meeting compared e-Conference in terms of equipping a range support. Future intentions to use one of these cooperative systems are examined questions Q29, Q30 and (if I'm you must select a suitable environment meeting will prefer SL Meeting / I will prefer e-conference to my connectivity). Also in this case there is no statistical evidence to the learner's preferences between SL Meeting and e-conference, even if the sample mean and median find out scoring slightly higher than $3 \mathrm{D}$ technology. It is important to refer to that we got to normal distribution of data as an outcome of the questionnaire Kolmogorove - Smirnov tests is a non parametric test for the equality of continuous, one-dimensional probability distributions that can be used to compare a sample with a reference probability distribution in this paper chose as a suitable mode for the questionnaire to be adapting and modify according to $[32,12,21]$, before running all the associated t-test, Figure 7 explain students as users understanding after the whole test.

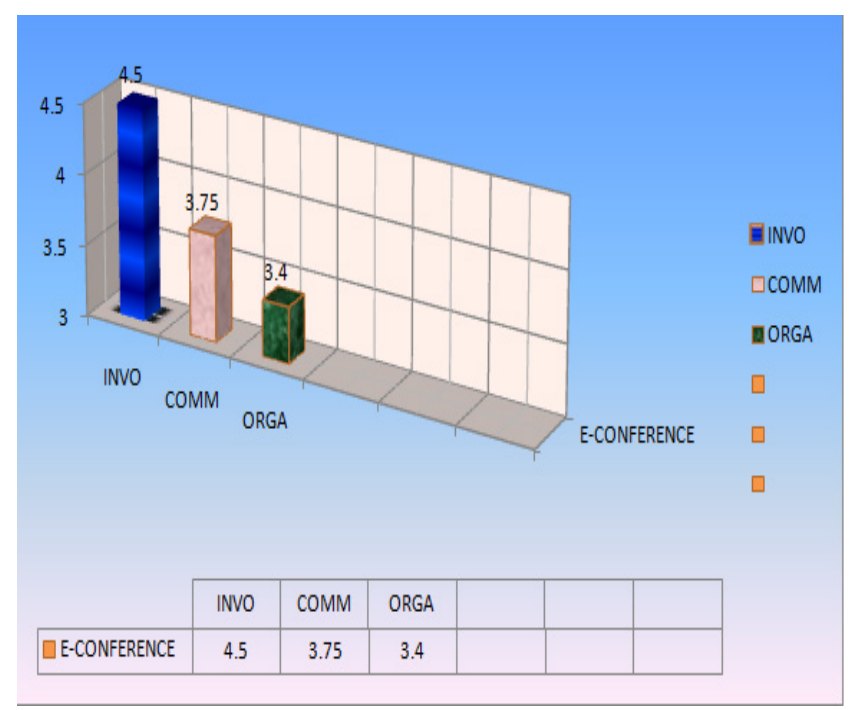

Figure 7. User understanding after the whole test

We dealt with the issues of Q17, Q19 Q21 (Avatar) to student Avatar perception assessment of where they are representative, social awareness and flexible and ease control. Questions Q18 Q28 and (VE) are specific to the proposed virtual environment evaluation, and inserted her value to the collaborative learning experience. Q24 and Q25 title of this nod insert value to the text communications. The reverse question Q25 outcomes before assembly. As shown in Figure 6, the outcomes detect a good and clear perception of nods and used during the learn cooperation activities alongside, a suitable impression and use of the 3D environment and a spreading sense of identifying students with their representatives synthetic and activities . Analysis of chat logs detected that the number of messages sent and exchanged between members of the group did not affected by the specific technology. Similar considerations also caught for the completion of all times Tasks in the end up.

\section{Conclusion}

In this study, we explained in a tentative study aiming at evaluating the value inserted by a $3 \mathrm{D}$ virtual environment cooperative learning activity and collaboration over the SL platform as virtual environment with high respect to Meeting system based on text-based synchronous communications. This paper is complementary to view a pilot study conducted in USM University in Malaysia in 2013 where the using has been compared to SL proposed cooperative learning group cooperation and face-to-face group to achieve collaborative.

In particular, these differences between the didactic two settings where performance and comfort with communication mode and posting role e- conference in comparison with traditional ways in education , 
enhancements have been compared, and global satisfaction also . Previous outcomes refer to that SL seems to be an effective delivery customizable environment that can be adopted as a replace for the actual world cooperation especially in the education sector .Outcomes of the experiment described in this study detected that the environment does not insert 3D elements distraction with high respect to specialized conferences text-based the system. In the technological landscape that seems to bring Browse the Internet and community interaction in the styles or context of 3D, If the third dimension does not interfere with normal participants communication in their field does not distract, it seems natural to adopt a more rich and flexible environment. Indeed, cooperative learning can be a specific task to perform in a broad range of activities and collaboration conducted in the virtual campus, such as remote lectures simultaneously to reduce time and efforts for both instructors and students in same time, and socialization activities in many sides in on hand, Virtual Lab, is a dangerous game, and others in other hand. Thus a range of activities imposes a perception of belonging to and community awareness of the case of the participants. Consequently, we are ending up ready to explain there is urgent demand to support collaborative learning in the Virtual Learning Environment VLE especially in higher education sectors.

\section{Acknowledgements}

We are very grateful to lecturers in CITM (PTPM) in USM for their appropriate and constructive suggestions to improve this study.

\section{REFERENCES}

[1] D. Aixia and D. Wang, "Factors Influencing Learner Attitudes Toward E-learning and Development of E-learning Environment Based on the Integrated E-learning Platform," International Journal of e-Education, e-Business, e-Management and e-Learning, vol. 1, pp. 264-68, 2011.

[2] F. di Cerbo, G. Dodero, and L. Papaleo, "Experiencing Personal Learning Environments and Networks using a 3D Space Metaphor."

[3] O. Sköld, "The effects of virtual space on learning: A literature review," First Monday, vol. 17, 2011.

[4] A. De Lucia, R. Francese, I. Passero, and G. Tortora, "Second Life Technological Transfer to Companies: the case study of the CC ICT-Sud Centre," Journal of e-Learning and Knowledge Society-English Version, vol. 5, 2009.

[5] M. Fominykh, "Collaborative Work on 3D Educational Content," Norwegian University of Science and Technology, 2012.

[6] S. Murad, I. Passero, R. Francese, and G. Tortora,
"VirtualHoP: Virtual Worlds for experimentation and concretization of technical drawing," in Global Engineering Education Conference (EDUCON), 2011 IEEE, 2011, pp. 888-894.

[7] R. HANEWALD, "LEARNERS AND COLLABORATIVE LEARNING IN VIRTUAL WORLDS: A Review of the Literature."

[8] A. De Lucia, R. Francese, I. Passero, and G. Tortora, "Trasferimento tecnologico alle imprese attraverso Second Life: il caso di studio del Centro di Competenza CC ICT-Sud," Journal of e-Learning and Knowledge Society-Italian Version (until 2012), vol. 5, 2009.

[9] B. Boniolo and C. Spadaro, "NEMO+ 3D, an integrated environment for advanced university teaching," Journal of e-Learning and Knowledge Society-English Version, vol. 6, 2010 .

[10] A. Nikolaou and C. Tsolakidis, "Three Dimensional Virtual Environments as a Tool for Development of Personal Learning Networks," International Journal of Emerging Technologies in Learning (iJET), vol. 8, pp. 79-88, 2013.

[11] A. M. Kaplan and M. Haenlein, "Users of the world, unite! The challenges and opportunities of Social Media," Business horizons, vol. 53, pp. 59-68, 2010.

[12] J. Mueller, K. Hutter, J. Fueller, and K. Matzler, "Virtual worlds as knowledge management platform-a practice perspective," Information Systems Journal, vol. 21, pp. 479-501, 2011

[13] M. Eisenbeiss, B. Blechschmidt, K. Backhaus, and P. A. Freund, "“The (real) world is not enough:" motivational drivers and user behavior in virtual worlds," Journal of Interactive Marketing, vol. 26, pp. 4-20, 2012.

[14] J. Cowdery, J. Kindred, A. Michalakis, and L. S. Suggs, "Promoting health in a virtual world: Impressions of health communication messages delivered in Second Life," First Monday, vol. 16, 2011.

[15] S. King, D. Chodos, E. Stroulia, M. Carbonaro, M. MacKenzie, A. Reid, et al., "Developing interprofessional health competencies in a virtual world," Medical education online, vol. 17, 2012.

[16] L. Sweigart and K. Hodson-Carlton, "Improving student interview skills: the virtual avatar as client," Nurse educator, vol. 38, pp. 11-15, 2013.

[17] C. Heinrich, R. R. Pennington, and R. Kuiper, "Virtual Case Studies in the Classroom Improve Student Knowledge," Clinical Simulation in Nursing, vol. 8, pp. e353-e361, 2012.

[18] M. Butina, D. Brooks, P. J. Dominguez, and G. M. Mahon, "Utilization of Virtual Learning Environments in the Allied Health Professions," Journal of allied health, vol. 42, pp. 7E-10E, 2013.

[19] H. D.-I. R. Zender, "Service-basierte Infrastruktur für pervasive Lehr-und Lernarrangements."

[20] R. Jamaludin, "Applying Second life in New 3DMetaverse Culture to Build Effective positioning Learning Platform for Arabic Language principles."

[21] M. N. K. Boulos, L. Hetherington, and S. Wheeler, "Second Life: an overview of the potential of $3-\mathrm{D}$ virtual worlds in 
medical and health education," Health Information \& Libraries Journal, vol. 24, pp. 233-245, 2007.

[22] T. Boellstorff, Coming of age in Second Life [electronic resource]: an anthropologist explores the virtually human: Princeton University Press, 2008.

[23] J. Kemp and D. Livingstone, "Putting a Second Life "metaverse" skin on learning management systems," in Proceedings of the Second Life education workshop at the Second Life community convention, 2006, pp. 13-18.

[24] A. De Lucia, R. Francese, I. Passero, and G. Tortora, "Development and evaluation of a virtual campus on Second Life: The case of SecondDMI," Computers \& Education, vol. 52, pp. 220-233, 2009.

[25] S. Warburton, "Second Life in higher education: Assessing the potential for and the barriers to deploying virtual worlds in learning and teaching," British Journal of Educational Technology, vol. 40, pp. 414-426, 2009.

[26] M. Rymaszewski, Second life: The official guide: John Wiley \& Sons, 2007.

[27] L. Jarmon, T. Traphagan, M. Mayrath, and A. Trivedi,
"Virtual world teaching, experiential learning, and assessment: An interdisciplinary communication course in Second Life," Computers \& Education, vol. 53, pp. 169-182, 2009.

[28] A. Gorini, A. Gaggioli, C. Vigna, and G. Riva, "A second life for eHealth: prospects for the use of 3-D virtual worlds in clinical psychology," Journal of medical Internet research, vol. $10,2008$.

[29] J. Wiecha, R. Heyden, E. Sternthal, and M. Merialdi, "Learning in a virtual world: experience with using second life for medical education," Journal of medical Internet research, vol. 12, 2010.

[30] L. Beard, K. Wilson, D. Morra, and J. Keelan, "A survey of health-related activities on second life," Journal of Medical Internet Research, vol. 11, 2009.

[31] S. C. Baker, R. K. Wentz, and M. M. Woods, "Using virtual worlds in education: Second Life ${ }^{\circledR}$ as an educational tool," Teaching of Psychology, vol. 36, pp. 59-64, 2009.

[32] C. Wankel and J. Kingsley, Higher education in Virtual Worlds: teaching and learning in Second Life: Emerald Group Publishing, 2009. 